\title{
Chemoselective Hydroboration of Propargylic Alcohols and Amines Using a Manganese(II) Catalyst
}

\author{
Aleksandra Brzozowska, ${ }^{\dagger}$ Viktoriia Zubar ${ }^{\dagger}$ Ruth-Christine Ganardi ${ }^{\dagger}$ and Magnus Rueping $*, \dagger, \uparrow$ \\ Institute of Organic Chemistry, RWTH Aachen University, Landoltweg 1, 52074 Aachen, Germany \\ *KAUST Catalysis Center (KCC), King Abdullah University of Science and Technology (KAUST), Thuwal 23955-6900, \\ Saudi Arabia
}
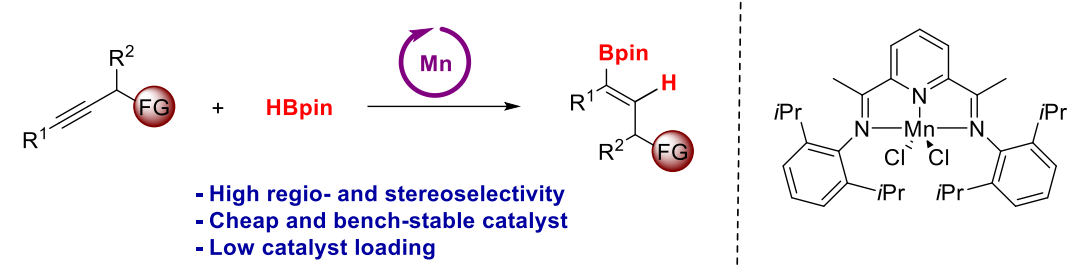

\begin{abstract}
The first manganese-catalyzed hydroboration of propargylic alcohols and amines as well as internal alkynes is reported. High regio- and stereoselectivity is achieved by applying $2 \mathrm{~mol} \%$ of a manganese pre-catalyst based on the readily accessible bis(imino)pyridine ligand and $\mathrm{MnCl}_{2}$ as metal source. Propargylic alcohols and amines, as well as symmetric internal alkynes, were efficiently converted into the corresponding functionalized alkenes, which can serve as important and valuable intermediates for further synthetic applications such as cross-coupling reactions.
\end{abstract}

The main goals of sustainable chemistry are associated with the application of relatively cheap and environmental benign catalysts, which allow transformations to be performed under mild reaction conditions with minimum waste production. ${ }^{1}$ In order to fulfill these requirements new catalytic systems are under continuous investigation. In this context, metalcatalyzed hydrometallation reactions gained interest due to their high atom-economic nature. Among the developed processes, the hydroboration is one of the most powerful transformations as the resulting boronic acid derivatives can undergo further useful derivatization in organic synthesis, for example in C-C bond formation via Suzuki-Miyaura crosscoupling reactions. ${ }^{2}$ Conventional methodologies providing synthetically useful alkenylboranes consist of metal exchange reaction occurring between organometallics (organolithium, Grignard reagents) and boron electrophiles, ${ }^{3}$ non-catalytic hydroboration reaction, ${ }^{4}$ and haloboration. ${ }^{5}$ However, selective hydrofunctionalization of alkynes still remains a challenging task due to the regioselectivity issues and formation of undesired byproducts. ${ }^{6}$ The catalytic hydroboration of internal alkynes is straightforward and an atom economic method for the synthesis of multi-substituted vinylboronates, which can serve as building blocks and intermediates in various reactions applied in both, academia and industry. ${ }^{7}$

The increasing interest in the application of first row transition metal catalysts in modern chemistry is strongly correlated with their more environmentally friendly nature, earth-abundance of metal precursors and often lower cost in comparison with commonly applied noble metals. Since 2016 manganese pincer complexes have been gaining a lot of attention as potential catalysts and proved to be a powerful tool, mainly in (de)hydrogenation and transfer hydrogenation reactions. ${ }^{8,9}$ The pincer ligands provide exceptional stabilities for the corresponding complexes and allow for the facile modification of their electronic and steric properties by modifying the socalled pincer-arms. ${ }^{10}$ Nonetheless, manganese-pincercatalyzed hydrofunctionalization still remains underexplored and known reports usually address the hydrosilylation of carbonyl groups. ${ }^{11}$ In this context, in 2014 Trovitch et al. reported the first application of manganese pincer complexes in the hydrosilylation of ketones. ${ }^{11 \mathrm{~b}}$ More recently, the group of Huang described an asymmetric approach. ${ }^{11 \mathrm{~d}}$ The hydroboration of multiple bonds by manganese-pincer complexes is even less developed, with only few reports regarding the conversion of carbonyl groups and alkenes. ${ }^{11 \mathrm{a}, 12}$ Based on our interest in the development of base metal catalyzed transformations we decided to investigate the hydroboration of internal alkynes, in particular propargylic alcohols and amines (Scheme 1).

Scheme 1. Manganese-catalyzed hydroboration of internal alkynes

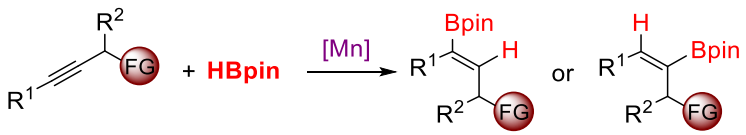

Our preliminary studies were performed applying TBDMSprotected 3-phenylprop-2-yn-1-ol 1a as model substrate and HBpin as borylating agent. The investigated catalyst precursors were activated in situ using $\mathrm{NaBHEt}_{3}$, allowing for application of easily accessible and bench stable manganese(II) complexes. 

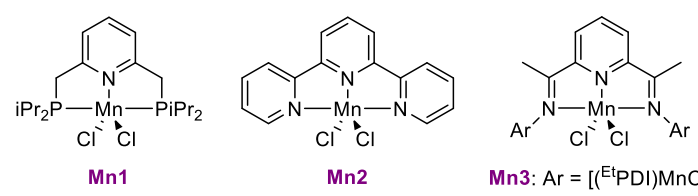

$\mathrm{Mn} 3: \mathrm{Ar}=\left[\left({ }^{\mathrm{Et}} \mathrm{PDI}\right) \mathrm{MnCl}_{2}\right]$ $\mathrm{Mn} 4: \mathrm{Ar}=\left[\left({ }^{(\mathrm{Pr} P D I}\right) \mathrm{MnCl}_{2}\right]$

Figure 1. Manganese complexes used in this study.

The initial reaction performed with 2 mol $\%$ of $\mathbf{M n} 1^{9 \mathrm{c}}$ (Figure 1) which was effective in the reduction of alkynes, did not show any conversion of the starting material (Table 1, entry 1). Likewise, use of the terpyridine complex $\mathbf{M n} \mathbf{2}^{12 b}$ also did not show any activity towards the formation of the desired product (entry 2). Bis(imino)pyridine(PDI)-based manganese complexes were our next choice. ${ }^{13,14}$ To our delight, the reaction of $1 \mathrm{a}$ with HBpin catalyzed by $2 \mathrm{~mol} \%$ of $\mathbf{M n 3}^{15}$ upon addition of $\mathrm{NaBHEt}_{3}(4 \mathrm{~mol} \%)$ at room temperature in hexane for $24 \mathrm{~h}$ resulted in the formation of trisubstituted alkene $2 \mathrm{a}-\beta$ in $76 \%$ yield (entry 3 ). Moreover, no formation of the $2 \mathrm{a}-\alpha$ isomer was detected, showing the high regioselectivity of the applied manganese system. The more sterically hindered $\mathbf{M n 4}{ }^{16}$ pre-catalyst proved to be the most effective, yielding the product in $88 \%$ yield (entry 4 ). A subsequent experiment has shown that no product is formed in the absence of the manganese catalyst (entry 5).

Table 1. Optimization of the reaction conditions ${ }^{a}$

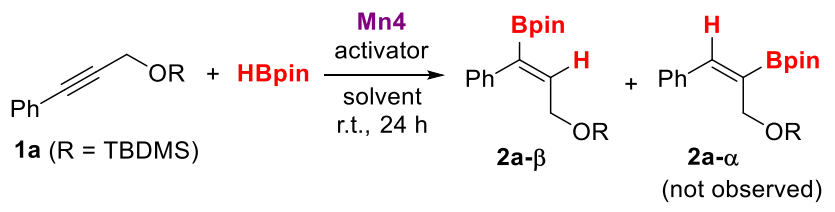

\begin{tabular}{|c|c|c|c|c|}
\hline entry & cat. $(\mathrm{mol} \%)$ & $\begin{array}{l}\text { activator (mol } \\
\%)\end{array}$ & solvent & $\begin{array}{l}\text { yield } \\
(\%)^{b}\end{array}$ \\
\hline 1 & Mn1 (2) & $\mathrm{NaBHEt}_{3}(4)$ & hexane & n.r. \\
\hline 2 & $\operatorname{Mn} 2(2)$ & $\mathrm{NaBHEt}_{3}(4)$ & hexane & n.r. \\
\hline 3 & Mn3 (2) & $\mathrm{NaBHEt}_{3}$ (4) & hexane & 76 \\
\hline 4 & Mn4 (2) & $\mathrm{NaBHEt}_{3}$ (4) & hexane & 88 \\
\hline 5 & - & $\mathrm{NaBHEt}_{3}(4)$ & hexane & n.r. \\
\hline 6 & Mn4 (2) & - & hexane & n.r. \\
\hline 7 & Mn4 (2) & $\mathrm{NaO} t \mathrm{Bu}(4)$ & hexane & n.r. \\
\hline 8 & Mn4 (2) & $\mathrm{KO} t \mathrm{Bu}(4)$ & hexane & 11 \\
\hline 9 & Mn4 (2) & $\mathrm{NaBHEt}_{3}$ (4) & toluene & 83 \\
\hline 10 & Mn4 (2) & $\mathrm{NaBHEt}_{3}(4)$ & $\mathrm{Et}_{2} \mathrm{O}$ & 19 \\
\hline 11 & Mn4 (2) & $\mathrm{NaBHEt}_{3}(4)$ & THF & n.r \\
\hline 12 & Mn4 (2) & $\mathrm{NaBHEt}_{3}(4)$ & $\mathrm{MeCN}$ & n.r \\
\hline 13 & $\mathbf{M n C l}_{2}(10)$ & $\mathrm{NaBHEt}_{3}(4)$ & hexane & n.r. \\
\hline $14^{c}$ & Mn4 (2) & $\mathrm{NaBHEt}_{3}(4)$ & hexane & 86 \\
\hline
\end{tabular}

${ }^{a}$ Reactions were performed on $0.25 \mathrm{mmol}$ scale with $2 \mathrm{~mL}$ of hexane and 2.5 equiv. of HBpin at r.t. in a culture tube under an inert atmosphere for $24 \mathrm{~h}$. ${ }^{b}$ Yields were determined by the $\mathrm{H}^{1}$ NMR analysis of the crude reaction mixture using mesitylene as an internal standard. ${ }^{c}$ The reaction was performed with a drop of mercury.
Further investigation of the reaction conditions proved the need for the addition of $\mathrm{NaBHEt}_{3}$ in order to form the catalytically active Mn-species (entry 6). Hence, we decided to check the catalyst performance upon activation with milder additives such as $\mathrm{NaO} t \mathrm{Bu}$ and $\mathrm{KO} t \mathrm{Bu}$, however both attempts were unsuccessful (entries 7 and 8). Next, we investigated the effect of the solvent on the reaction outcome. Only aprotic and non-polar reaction media were suitable for our transformation. The reaction performed in toluene led to $83 \%$ of product (entry 9), whereas in sharp contrast only $19 \%$ of product could be observed when $\mathrm{Et}_{2} \mathrm{O}$ was applied (entry 10). Reactions performed in $\mathrm{THF}$ and $\mathrm{MeCN}$ led to no conversion, probably due to the coordinative nature of these solvents and poisoning effect on the catalyst (entries 11 and 12). The presence of the bis(imino)pyridine ligand was essential for the manganesecatalyzed hydroboration of alkynes, as the sole $\mathrm{MnCl}_{2}$ did not show activity even when applying higher catalyst loading (entry 13). Addition of a drop of mercury did not affect the catalytic performance of $\left[\left({ }^{i \mathrm{Pr} P D I}\right) \mathrm{MnCl}_{2}\right]$, suggesting a homogenous nature of the applied catalyst (entry 14).

With the optimized reaction conditions in hand we explored the scope of the reaction with Mn4 complex as pre-catalyst and the results are summarized in Scheme 2. Under the developed reaction conditions various substrates were successfully converted into the corresponding products preserving the high stereo- and regioselectivity towards formation of $\beta$-substituted ( $Z$ )-alkenes. Most alkynes reacted smoothly in the presence of $2 \mathrm{~mol} \%$ catalyst. Alkynes containing electron withdrawing as well as electron donating groups could be effectively converted into trisubstituted alkenes. Propargylic functionalized alcohols bearing a methyl substituent in different positions of the aromatic ring underwent hydroboration leading to the corresponding products $\mathbf{2 b}$-d in high yields. Phenyl substituted alkyne 1e also reacted smoothly giving the corresponding alkene in $91 \%$ yield. Additionally, alkynes containing a halogen-substituted aromatic ring proved to be suitable for our protocol (products 2f-h). Substrate 1i containing a stronger electron-withdrawing $\mathrm{CF}_{3}$ substituent yielded the corresponding product in high yield $(88 \%)$. In general, alkynes with ortho- and metasubstituents on the aromatic ring required application of higher catalyst loading, nevertheless high yields were obtained. Moreover, our method worked efficiently for tiophene-derived alkyne 1j, which was successfully reduced giving the corresponding product in $95 \%$ yield. Alkynes with enhanced steric hindrance on the carbon atom in the vicinity of the alcohol moiety were easily converted into the corresponding products 2k-m in high yields. We also demonstrated that aliphatic alkynes can be successfully applied in our protocol (2n).

In order to show the synthetic utility of our method we performed the Mn-catalyzed hydroboration on larger scale. Under the given conditions, $1 \mathrm{mmol}$ of tert-butyldimethyl((3phenylprop-2-yn-1-yl)oxy)silane 1a was successfully transformed into $85 \%$ of isolated functionalized alkene $\mathbf{2 a}$, proving that our protocol can be scaled-up without any loss of efficiency. 
Scheme 2. Manganese-catalyzed hydroboration of TBDMSprotected hydroxyalkynes ${ }^{a}$

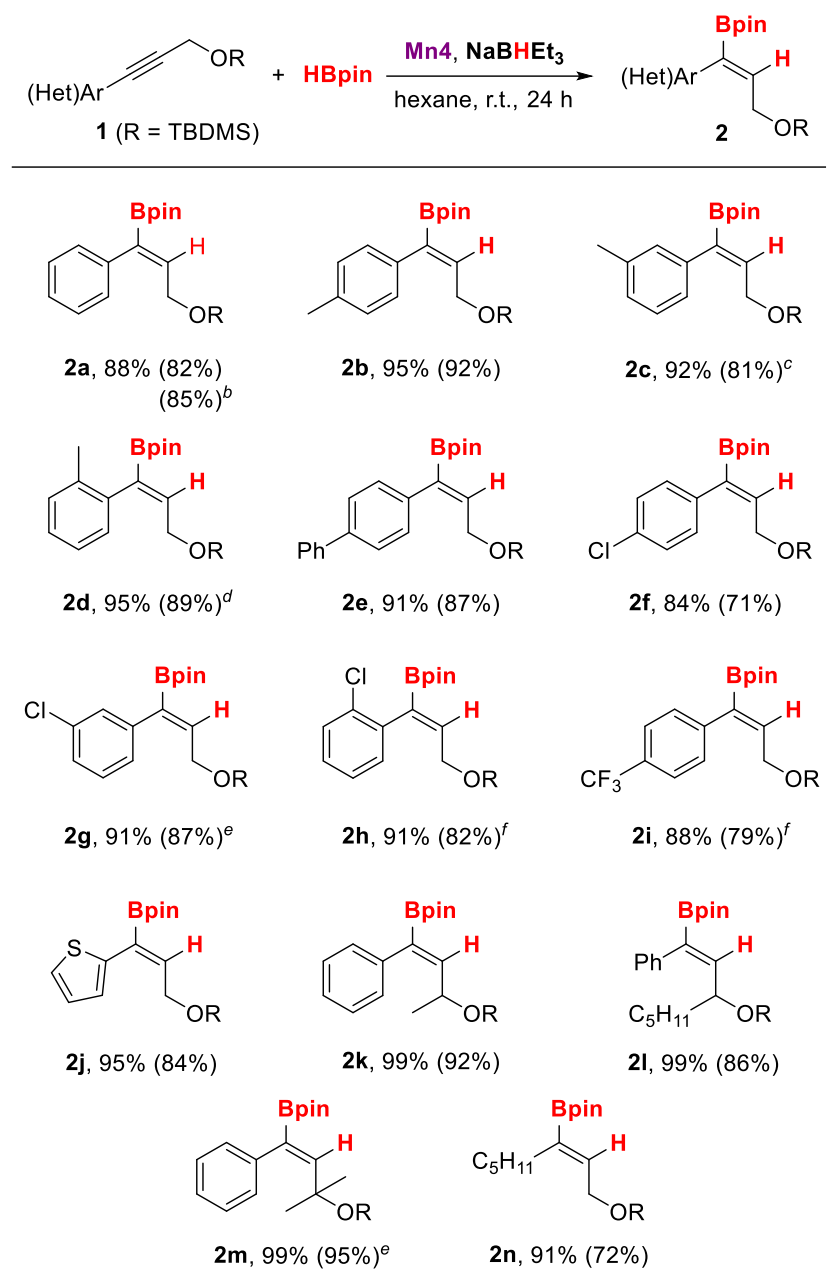

${ }^{a}$ Reaction conditions: 1 (0.25 mmol), HBpin $(0.375 \mathrm{mmol})$, catalyst Mn4 (2 mol \%) and $\mathrm{NaBHEt}_{3}(4 \mathrm{~mol} \%)$ in hexane $(2 \mathrm{~mL})$ were stirred at r.t. for $24 \mathrm{~h}$ in a culture tube under an inert atmosphere. Yields were determined by $\mathrm{H}^{1} \mathrm{NMR}$ analysis of the crude reaction mixture using mesitylene as an internal standard. Yields after column chromatography given in parentheses. ${ }^{b}$ Yield for the reaction on $1 \mathrm{mmol}$ scale. ${ }^{c} \mathbf{M n} 4$ (8 mol \%), $\mathrm{NaBHEt}_{3}(16$ mol \%). ${ }^{d} \mathbf{M n} 4$ (3 mol \%), $\mathrm{NaBHEt}_{3}(6 \mathrm{~mol} \%) .{ }^{e} \mathbf{M n} 4$ (10 mol \%), $\mathrm{NaBHEt}_{3}(20 \mathrm{~mol} \%) .{ }^{f} \mathbf{M n} 4$ (4 mol \%), $\mathrm{NaBHEt}_{3}(8 \mathrm{~mol} \%)$.

After the successful hydroboration of propargylic functionalized alcohols, we focused our attention to the hydroboration of related propargylic amines. The expected products, trisubstituted enamines, can be applied as valuable synthons and building blocks in the synthesis of heterocycles and bioactive amines. ${ }^{17}$ To our delight, dibenzyl-protected amines bearing both electron-donating and electronwithdrawing substituents in different positions of the aryl ring proved to be suitable substrates (Scheme 3, 4a-4f). Moreover, tiophene-derived propargylic amine reacted smoothly, yielding the corresponding functionalized alkene $\mathbf{4 g}$ in $85 \%$ yield.
Scheme 3. Manganese-catalyzed hydroboration of $\mathrm{Bn}$ protected propargylic amines $^{a}$

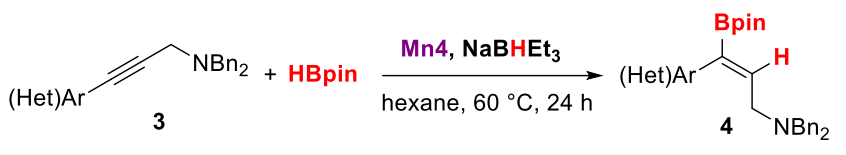

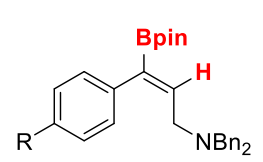

$\mathrm{R}=\mathrm{H}: \quad 4 \mathrm{a}, 93 \%(82 \%)$

$\mathrm{R}=\mathrm{Me}: \mathbf{4 b}, 89 \%(52 \%)$

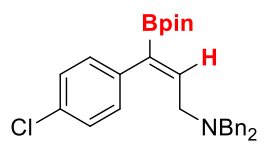

4d, $89 \%(57 \%)$

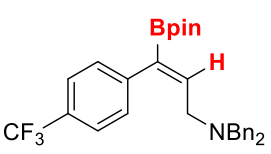

4f, $84 \%(51 \%)^{b}$

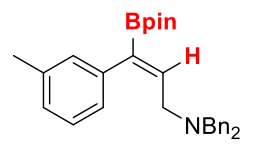

4c, $86 \%(49 \%)$

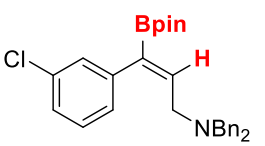

4 e, $80 \%(46 \%)$

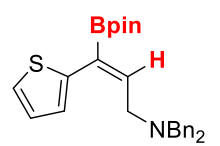

$4 \mathbf{g}, 95 \%(85 \%)$
${ }^{a}$ Reaction conditions: 3 (0.25 mmol), HBpin (0.375 mmol), Mn4 $(4 \mathrm{~mol} \%)$ and $\mathrm{NaBHEt}_{3}(8 \mathrm{~mol} \%)$ in hexane $(2 \mathrm{~mL})$ were stirred at $60{ }^{\circ} \mathrm{C}$ for $24 \mathrm{~h}$ in a culture tube under an inert atmosphere. Yields were determined by $\mathrm{H}^{1}$ NMR analysis of the crude reaction mixture using hexamethyldisiloxane as an internal standard. Yields after column chromatography given in parentheses. ${ }^{b} \mathbf{M n} 4$ (6 mol \%), NaBHEt $3(12 \mathrm{~mol} \%)$.

Furthermore, we decided to demonstrate that the obtained borylated products can serve as substrates for the stereochemically controlled synthesis of trisubstituted olefins. For this purpose, the obtained vinylboronate 2a was applied in Suzuki-Miyaura cross-coupling with bromobenzene in the presence of $5 \mathrm{~mol} \%$ of $\mathrm{Pd}(\mathrm{OAc})_{2}$, which resulted in $70 \%$ of isolated product 2aa (Scheme 4).

Scheme 4. Synthetic application of the obtained vinylboronates

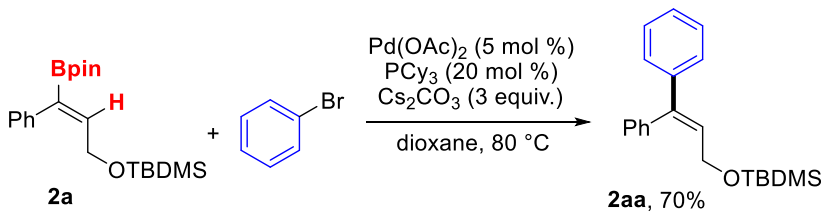

Finally, our catalytic system was active also in the hydrofunctionalization reaction of symmetrically substituted aromatic and aliphatic internal alkynes (Scheme 5). Interestingly, complex Mn3 showed higher activity than Mn4 and led to the formation of syn-addition products exclusively in high yields. Alkynes with methyl substituents in different positions of the aromatic ring reacted smoothly yielding the corresponding products $\mathbf{6 b - c}$ in high yields. Alkynes 5d-f enriched with electron-withdrawing substituents were also successfully applied in hydroboration. Reactions with 
thiophene-derived substrates $\mathbf{5 g}-\mathbf{h}$ proceeded almost quantitatively, giving $92 \%$ and $96 \%$ of the corresponding product $\mathbf{6 g}$ and $\mathbf{6 h}$. We were glad to observe, that aliphatic alkyne $\mathbf{5 i}$ reacted to give $98 \%$ of the borylated product.

Scheme 5. Manganese-catalyzed hydroboration of symmetric alkynes $^{a}$

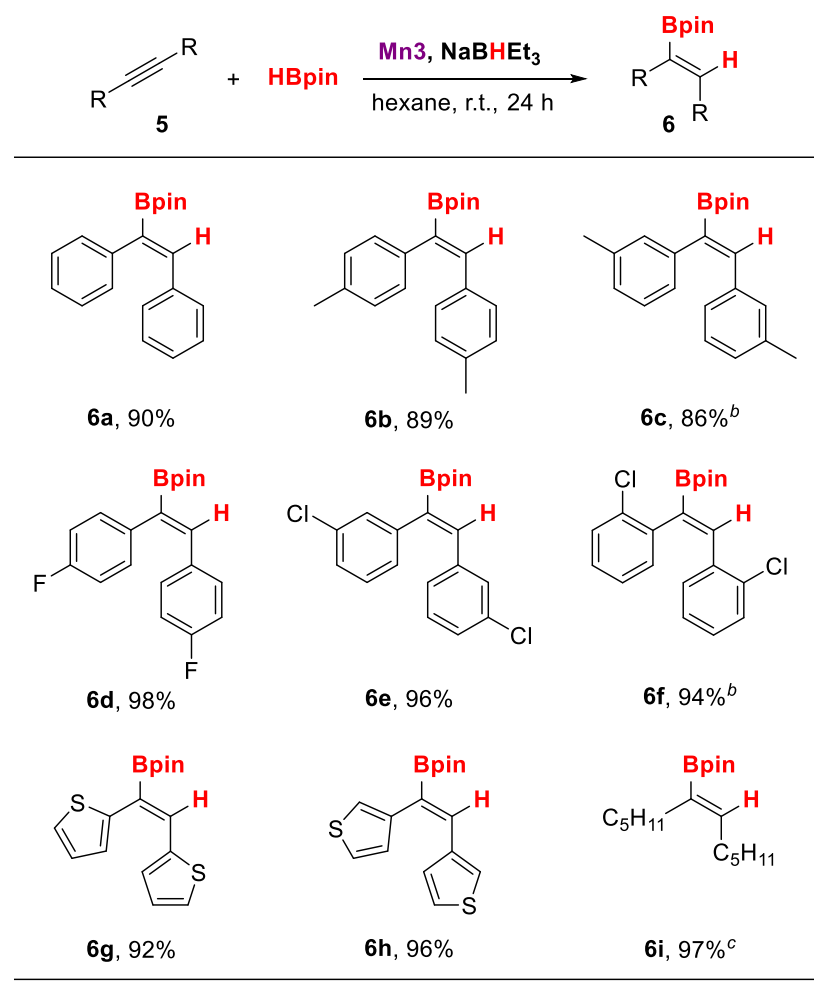

${ }^{a}$ Reaction conditions: 5 (0.25 mmol), HBpin (0.375 mmol), catalyst Mn3 (2 mol \%) and $\mathrm{NaBHEt}_{3}$ (4 mol \%) in hexane $(1 \mathrm{~mL})$ were stirred at r.t. for $24 \mathrm{~h}$ in a culture tube under an inert atmosphere. Isolated yields are given. ${ }^{b} \mathbf{M n 3}$ (4 mol \%), $\mathrm{NaBHEt}_{3}$ (8 mol \%). ${ }^{c} \mathbf{M n 3}$ (6 mol \%), NaBHEt3 (12 mol \%).

In conclusion, the first example of a manganese-catalyzed hydroboration of alkynes, which is characterized by high regio- and stereoselectivity, is presented. The hydrofunctionalization of various functionalized internal alkynes as well as propargylic alcohols and amines proceeds under homogenous reaction conditions and leads to the formation of valuable alkenylboranes in good yields. The corresponding products can serve as valuable intermediates as demonstrated by their application in cross-coupling reactions.

\section{ASSOCIATED CONTENT}

\section{Supporting Information}

The Supporting Information is available free of charge on the ACS Publications website.

Experimental procedures and characterization of compounds (file type, i.e., PDF)

\section{AUTHOR INFORMATION}

\section{Corresponding Author}

*Email: magnus.rueping@ rwth-aachen.de

Notes

The authors declare no competing financial interest.

\section{REFERENCES}

(1) Marion, P.; Bernela, B.; Piccirilli, A.; Estrine, B.; Patouillard, N.; Guilbot, J.; Jérôme, F., Sustainable chemistry: how to produce better and more from less? Green Chem. 2017, 19, 4973-4989.

(2) (a) Lennox, A. J.; Lloyd-Jones, G. C., Selection of boron reagents for Suzuki-Miyaura coupling. Chem. Soc. Rev. 2014, 43, 412-443; (b) Miyaura, N.; Suzuki, A., Palladium-Catalyzed CrossCoupling Reactions of Organoboron Compounds. Chem. Rev. 1995, 95, 2457-2483.

(3) Brown, H. C.; Imai, T.; Bhat, N. G., Vinylic organoboranes. 7. Stereoselective synthesis of (E)-(1-substituted-1-alkenyl)boronic esters by the nucleophilic substitution of (Z)-(1-bromo-1alkenyl)boronic esters with organolithium or Grignard reagents. Isolation and oxidation to ketones. J. Org. Chem. 1986, 51, 52775282.

(4) (a) Brown, H. C.; Gupta, S. K., Hydroboration. XXXIX. 1,3,2Benzodioxaborole (catecholborane) as a new hydroboration reagent for alkenes and alkynes. General synthesis of alkane- and alkeneboronic acids and esters via hydroboration. Directive effects in the hydroboration of alkenes and alkynes with catecholborane. J. Am. Chem. Soc. 1975, 97, 5249-5255; (b) Hoshi, M.; Shirakawa, K.; Arase, A., Preparation of (E)-1-Alkenylboronic Acid Pinacol Esters via Transfer of Alkenyl Group from Boron to Boron. Synthesis 2004, 1814-1820; (c) Tucker, C. E.; Davidson, J.; Knochel, P., Mild and stereoselective hydroborations of functionalized alkynes and alkenes using pinacolborane. J. Org. Chem. 1992, 57, 3482-3485.

(5) Satoh, Y.; Serizawa, H.; Miyaura, N.; Hara, S.; Suzuki, A., Organic synthesis using haloboration reactions 11. A formal carboboration reaction of 1-alkynes and its application to the di- and trisubstituted alkene synthesis. Tet. Lett. 1988, 29, 1811-1814.

(6) Trost, B. M.; Ball, Z. T., Addition of Metalloid Hydrides to Alkynes: Hydrometallation with Boron, Silicon, and Tin. Synthesis 2005, 853-887.

(7) Cherney, A. H.; Kadunce, N. T.; Reisman, S. E., Enantioselective and Enantiospecific Transition-Metal-Catalyzed Cross-Coupling Reactions of Organometallic Reagents To Construct C-C Bonds. Chem. Rev. 2015, 115, 9587-8652.

(8) For reviews on the topic of manganese-pincer catalyzed transformations, see: (a) Garbe, M.; Junge, K.; Beller, M., Homogeneous Catalysis by Manganese-Based Pincer Complexes. Eur. J. Org. Chem. 2017, 4344-4362; (b) Mukherjee, A.; Milstein, D., Homogeneous Catalysis by Cobalt and Manganese Pincer Complexes. ACS Catal. 2018, 8, 11435-11469; (c) Maji, B.; Barman, M., Recent Developments of Manganese Complexes for Catalytic Hydrogenation and Dehydrogenation Reactions. Synthesis 2017, 49, 3377-3393; For general reviews on manganese-catalysed reactions, see: (d) Zell, T.; Langer, R. From Ruthenium to Iron and Manganese-A Mechanistic View on Challenges and Design Principles of Base-Metal Hydrogenation Catalysts. ChemCatChem 2018, 10, 1930-1940. (e) Kallmeier, F.; Kempe, R. Manganese Complexes for (De)Hydrogenation Catalysis: A Comparison to Cobalt and Iron Catalysts. Angew. Chem., Int. Ed. 2018, 57, 46-60. (f) Gorgas, N.; Kirchner, K. Isoelectronic Manganese and Iron Hydrogenation/Dehydrogenation Catalysts: Similarities and Divergences. Acc. Chem. Res. 2018, 51, 1558-1569. (g) Filonenko, G. A.; van Putten, R.; Hensen, E. J. M.; Pidko, E. A. Catalytic (de)hydrogenation promoted by non-precious metals - Co, Fe and Mn: recent advances in an emerging field. Chem. Soc. Rev. 2018, 47, 1459-1483. (h) Valyaev, D. A.; Lavigne, G.; Lugan, N. Manganese organometallic compounds in homogeneous catalysis: Past, present, and prospects. Coord. Chem. Rev. 2016, 308, 191-235. (i) Carney, J. R.; Dillon, B. R.; Thomas, S. P. Recent Advances of Manganese Catalysis for Organic Synthesis. Eur. J. Org. Chem. 2016, 3912-3929. (j) Liu, W.; Ackermann, L. Manganese-Catalyzed C-H Activation. ACS Catal. 2016, 6, 3743-3752. (k) Wang, C. Manganese-Mediated 
C-C Bond Formation via C-H Activation: From Stoichiometry to Catalysis. Synlett 2013, 24, 1606-1613.

(9) Recent Mn-catalysis from our group: (a) Zubar, V.; Lebedev, Y.; Azofra, L. M.; Cavallo, L.; El-Sepelgy, O.; Rueping, M., Hydrogenation of $\mathrm{CO}_{2}$-Derived Carbonates and Polycarbonates to Methanol and Diols by Metal-Ligand Cooperative Manganese Catalysis. Angew Chem Int Ed 2018, 57, 13439. (b) Wang, C.; Maity, B.; Cavallo, L.; Rueping M., Manganese catalyzed regioselective C-H alkylation of heteroarenes: Experiment and Computation. Org. Lett. 2018, 20, 3105-3108. (c) Wang, C.; Rueping, M., Rhenium and Manganese-Catalyzed Selective Alkenylation of Indoles. ChemCatChem 2018, 10, 2681-2685. (d) Brzozowska, A.; Azofra, L. M.; Zubar, V.; Atodiresei, I.; Cavallo, L.; Rueping, M.; El-Sepelgya O., Highly Chemo- and Stereoselective Transfer Semihydrogenation of Alkynes Catalyzed by a Stable, Well-defined Manganese(II) Complex, ACS Catal. 2018, 8, 4103-4109. (e) Wang, C.; Wang, A.; Rueping, M., Manganese catalyzed C-H functionalizations involving an unexpected heteroaryl-shift Angew. Chem. Int. Ed. 2017, 56, 99359938. (f) Borghs, J. C., Tran, M. A., Sklyaruk, J., Rueping, M.; ElSepelgy O., Sustainable Alkylation of Nitriles with Alcohols by Manganese Catalysis. J. Org. Chem. 2019, 84, 7927-7935. (g) Borghs, J. C.; Azofra, L. M.; Biberger, T.; Linnenberg, O.; Cavallo, L.; Rueping M.; El-Sepelgy O., Manganese Catalyzed Multicomponent Synthesis of Pyrroles via Acceptorless Dehydrogenation Hydrogen Autotransfer Catalysis: Experiment and Computation, J. C. Borghs, L. M. Azofra, T. Biberger, O. Linnenberg, L. Cavallo, M. Rueping O. El-Sepelgy ChemSusChem 2019, 12, 3083-3088. (h) Sklyaruk, J.; Borghs, J. C.; El-Sepelgy, O.; Rueping, M., Catalytic C1-Alkylation with Methanol and Isotope Labelled Methanol, J. Sklyaruk, J. C. Borghs, O. El-Sepelgy, M. Rueping, Angew. Chem. Int. Ed 2019, 58, 775-779. (i) Matador, E.; Brzozowska, A; El-Sepelgy, O.; Rueping M., C-Alkylation of Secondary Alcohols with Primary Alcohols through Manganese Catalyzed Double Hydrogen Autotransfer. ChemSusChem 2019, 12, 3099-3102. (j) Borghs, J. C.; Lebedev, Y.; Rueping, M; El-Sepelgy O., Sustainable Manganese Catalyzed Solvent-free Synthesis of Pyrroles from 1,4-Diols and Primary Amines. Org. Lett. 2019, 21, 7074.

(10) (a) Morales-Morales, D., Pincer compounds: chemistry and applications Elsevier Amsterdam, 2018 (b) Stradiotto, M.; Lundgren, R. J.; John, W.; Sons, Ligand design in metal chemistry : reactivity and catalysis. John Wiley \& Sons: Chichester, 2016; (c) Van Koten, G.; Milstein, D., Organometallic Pincer Chemistry. Springer Berlin: Berlin, 2014; (d) Peris, E.; Crabtree, R. H., Key factors in pincer ligand design. Chem. Soc. Rev. 2018, 47, 1959-1968.

(11) (a) Carney, J. R.; Dillon, B. R.; Campbell, L.; Thomas, S. P., Manganese-Catalyzed Hydrofunctionalization of Alkenes. Angew. Chem. Int. Ed. 2018, 57, 10620-10624; (b) Mukhopadhyay, T. K.; Flores, M.; Groy, T. L.; Trovitch, R. J., A highly active manganese precatalyst for the hydrosilylation of ketones and esters. J. Am. Chem. Soc. 2014, 136, 882-885; (c) Ghosh, C.; Mukhopadhyay, T. K.; Flores, M.; Groy, T. L.; Trovitch, R. J., A Pentacoordinate Mn(II) Precatalyst That Exhibits Notable Aldehyde and Ketone
Hydrosilylation Turnover Frequencies. Inorg. Chem. 2015, 54, 10398-406; (d) Ma, X.; Zuo, Z.; Liu, G.; Huang, Z., ManganeseCatalyzed Asymmetric Hydrosilylation of Aryl Ketones. ACS Omega 2017, 2, 4688-4692; (e) Mukhopadhyay, T. K.; Rock, C. L.; Hong, M.; Ashley, D. C.; Groy, T. L.; Baik, M. H.; Trovitch, R. J., Mechanistic Investigation of Bis(imino)pyridine Manganese Catalyzed Carbonyl and Carboxylate Hydrosilylation. J. Am. Chem. Soc. 2017, 139, 4901-4915.

(12) (a) Vasilenko, V.; Blasius, C. K.; Wadepohl, H.; Gade, L. H., Mechanism-Based Enantiodivergence in Manganese Reduction Catalysis: A Chiral Pincer Complex for the Highly Enantioselective Hydroboration of Ketones. Angew. Chem. Int. Ed. 2017, 56, 83938397; (b) Zhang, G.; Zeng, H.; Wu, J.; Yin, Z.; Zheng, S.; Fettinger, J. C., Highly Selective Hydroboration of Alkenes, Ketones and Aldehydes Catalyzed by a Well-Defined Manganese Complex. Angew. Chem. Int. Ed. 2016, 55, 14369-14372; (c) Erken, C.; Kaithal, A.; Sen, S.; Weyhermuller, T.; Hölscher, M.; Werle, C.; Leitner, W., Manganese-catalyzed hydroboration of carbon dioxide and other challenging carbonyl groups. Nat. Commun. 2018, 9, 4521.

(13) (a) Bart, S. C.; Lobkovsky, E.; Chirik, P. J., Preparation and molecular and electronic structures of iron $(0)$ dinitrogen and silane complexes and their application to catalytic hydrogenation and hydrosilation. J. Am. Chem. Soc. 2004, 126, 13794-807; (b) Greenhalgh, M. D.; Jones, A. S.; Thomas, S. P., Iron-Catalysed Hydrofunctionalisation of Alkenes and Alkynes. ChemCatChem 2015, 7, 190-222; (c) Obligacion, J. V.; Chirik, P. J., Highly selective bis(imino)pyridine iron-catalyzed alkene hydroboration. Org. Lett. 2013, 15, 2680-2683; (d) Tondreau, A. M.; Atienza, C. C.; Weller, K. J.; Nye, S. A.; Lewis, K. M.; Delis, J. G.; Chirik, P. J., Iron catalysts for selective anti-Markovnikov alkene hydrosilylation using tertiary silanes. Science 2012, 335, 567-570; (e) Greenhalgh, M. D.; Thomas, S. P., Chemo-, regio-, and stereoselective iron-catalysed hydroboration of alkenes and alkynes. Chem. Commun. 2013, 49, 11230-11232.

(14) (a) Obligacion, J. V.; Chirik, P. J., Bis(imino)pyridine cobaltcatalyzed alkene isomerization-hydroboration: a strategy for remote hydrofunctionalization with terminal selectivity. J. Am. Chem. Soc. 2013, 135, 19107-19110; (b) Obligacion, J. V.; Neely, J. M.; Yazdani, A. N.; Pappas, I.; Chirik, P. J., Cobalt catalyzed z-selective hydroboration of terminal alkynes and elucidation of the origin of selectivity. J. Am. Chem. Soc. 2015, 137, 5855-5858.

(15) R.-Q. Fan, G.-H. Y., X.-D. Ding, J. Chen, Y.-L. Yang, Syntheses, crystal structures and catalytic performance of 2,6bis(imino) pyridyl manganese complexes. Chem. J. Chin. Univ. 2011, $32,1239-1243$

(16) Reardon, D.; Aharonian, G.; Gambarotta, S.; Yap, G. P. A., Mono- and Zerovalent Manganese Alkyl Complexes Supported by the $\alpha, \alpha^{6}$-Diiminato Pyridine Ligand: Alkyl Stabilization at the Expense of Catalytic Performance. Organometallics 2002, 21, 786-788.

(17) Skoda, E. M.; Davis, G. C.; Wipf, P., Allylic Amines as Key Building Blocks in the Synthesis of (E)-Alkene Peptide Isosteres. Org. Process Res. Dev. 2012, 16, 26-34. 